\title{
SHORT-TERM SWASH ZONE BEACH PROFILE CHANGE MODEL FOCUSING ON BERM FORMATION AND EROSION
}

\author{
Takayuki Suzuki' and Yoshiaki Kuriyama²
}

\begin{abstract}
A short-term swash zone beach profile change model focusing on berm formation and erosion was proposed using a 2.5-year data set of beach profiles and offshore waves. The investigation area was set from the maximum wave run-up position to the shoreline position at the mean tide level. The model was applied for the calculation of three months beach profile change. The results revealed that the model well predicts the beach profile change including the berm formation and erosion in a qualitative sense. Also, the variation trend of the calculated beach slope at the shoreline position of the mean tide level show a good agreement with that of the observed beach slope.
\end{abstract}

Keywords: berm; swash zone; beach profile change; modeling; field data

\section{INTRODUCTION}

In the swash zone, sediments are transported by wave run-up and run-down, and the beach profile is changed by the imbalance of its onshore and offshore sediment transport rates. Owing to these sediment transport rates, berms are commonly formed between a mean sea level and a maximum wave run-up level. During mild wave conditions, berms form on the foreshores (e.g., Thomas and Baba 1986, Katoh and Yanagishima 1992). In contrast, berm erosion occurs when the enhanced wave run-up passes through the berm crest (Katoh and Yanagishima 1993).

The sediment transport rates in the swash zone have been studied by a number of researchers. Osborne and Rooker (1997) reported that net transport is potentially sensitive to small variation of the phase angle between suspended sediment concentration and velocity in uprush and backwash cycle. Moreover, Puleo et al. (2000) studied the swash zone sediment transport using field data. They found that vertical profiles of backwash differed from that of the uprush and that bore-derived turbulence may affect local sediment transport. Suzuki et al. (2007) investigated the characteristics of the distributions of the cross-shore sediment transport rates for berm formation and erosion.

Also, numerical models for the swash zone have been proposed. Larson et al. (2004) proposed a sediment transport formula for foreshore and compared the beach profile change with the observed data. Although the optimum value on the main calibration coefficient displayed some variation between experiments, the model shows qualitatively agreement. Baldock et al. (2007) proposed a probabilistic-deterministic model for swash zone sediment transport and applied the model to predict cross-shore beach profile change under random waves. Suzuki and Kuriyama (2008) proposed the models of the spatial distributions of the cross-shore sediment transport rates for berm formation and erosion with the offshore wave energy flux and the berm height, respectively. However, sediment transport models in the foreshore, where berms are formed and eroded, have not been well developed.

The objective of this study is to develop a short-term swash zone beach profile change model focusing on berm formation and erosion on the basis of a 2.5 -year data set of beach profile.

\section{DATA DESCRIPTION}

\section{Beach Profile Data}

Beach profile data were obtained from August 1987 to January 1990 at Hazaki Oceanographical Research Station (HORS), a research facility for field measurements of various phenomena in the nearshore zone on the Hasaki coast of Japan facing the Pacific Ocean (Fig. 1). HORS has a 427-mlong pier, which is located perpendicular to the shore. The cross-shore distance along the pier is defined relative to the reference point of HORS, located near the entrance of the pier, and the seaward direction is set as being positive.

The beach profiles along the pier were measured at $5 \mathrm{~m}$ intervals every day except weekends and holidays, with a $3 \mathrm{~kg}$ lead from the pier and with a level and a staff shoreward of the pier. All thorough the year, the median sediment diameter is $0.18 \mathrm{~mm}$ and almost uniform along the pier. The Hasaki coast is stable, and the bathymetry around HORS is almost uniform alongshore. The high, mean and

\footnotetext{
${ }^{1}$ Department of Civil Engineering, Yokohama National University, Tokiwadai 79-5, Hodogaya, Yokohama, Kanagawa 240-8501, Japan

${ }^{2}$ Director of Marine Environment and Engineering Department, Port and Airport Research Institute, Nagase 3-1-1, Yokosuka, Kanagawa 239-0826, Japan
} 
low water levels based on the datum level at Hasaki coast (Tokyo Peil $-0.687 \mathrm{~m}$ ) are $1.25 \mathrm{~m}, 0.65 \mathrm{~m}$, and $-0.20 \mathrm{~m}$, respectively.

Figure 2 shows the mean beach profile and its standard deviation in the surf zone, the foreshore and the backshore. The seaward position at the intersection of the mean beach profile with the mean water level is $x=9.5 \mathrm{~m}$, and beach slope around the shoreline position is about $1 / 40$. From the figure, several peaks can be seen in the distribution of the standard deviation. The relatively high values around the seaward distance of $x=-10 \mathrm{~m}$ are due to berm formation and erosion.

\section{Offshore Wave Data}

An Ultra Sonic Wave gage (USW) sensor was mounted at a water depth of $23.4 \mathrm{~m}$ offshore the port of Kashima, which is located about $8 \mathrm{~km}$ north from HORS (see Fig. 1). The offshore waves were measured for 20 minutes every 2 hours by the USW. During the investigation period, the averaged offshore significant wave height and period were $1.65 \mathrm{~m}$ (varied from $0.37 \mathrm{~m}$ to $6.49 \mathrm{~m}$ ) and $8.51 \mathrm{~s}$ (varied from $4.88 \mathrm{~s}$ to $17.2 \mathrm{~s}$ ), respectively.

The offshore wave energy flux is calculated from the offshore wave height and the wave celerity.

$$
E_{f}=\frac{1}{16} \rho g\left(H_{1 / 3}\right)_{0}^{2} C_{g 0}[\mathrm{kN} / \mathrm{s}]
$$

where $\rho$ is the sea water density, $g$ is the gravity acceleration, $H_{1 / 3}$ is the significant wave height and $C_{\mathrm{g} 0}$ is the wave celerity. The offshore wave energy flux is positive for onshore-ward.

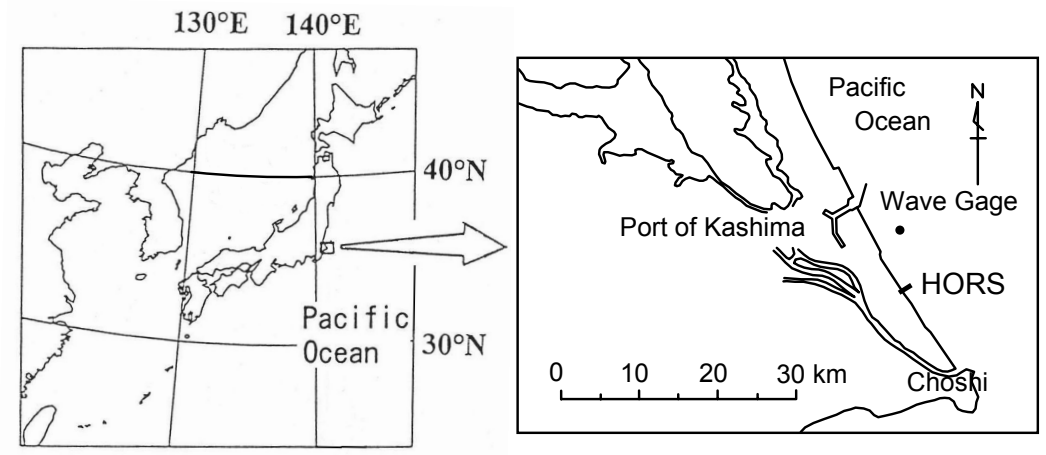

Figure 1. Location of Hazaki Oceanographical Research Station (HORS).

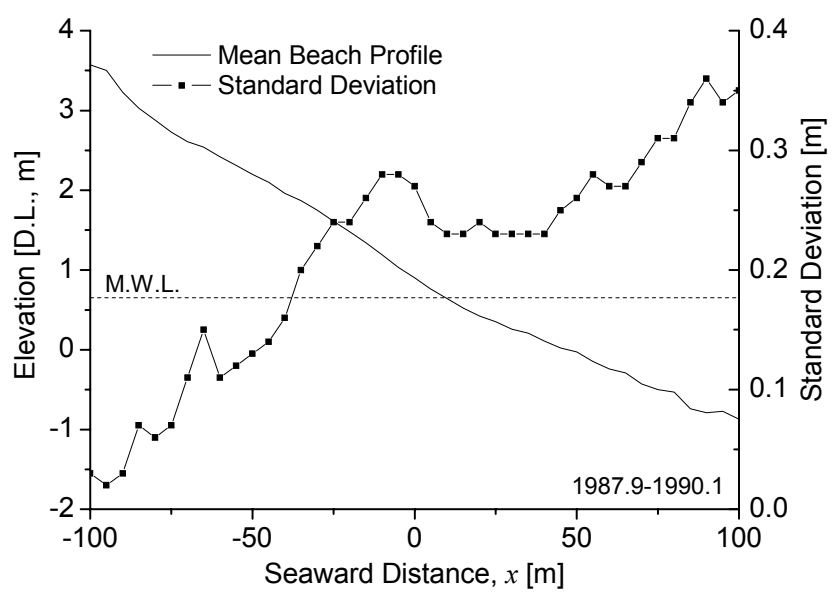

Figure 2. Mean beach profile and its standard deviation. 


\section{Wave Run-up Level}

The shoreline position varies according to beach topography, tide and wave set-up near the shoreline. In this study, the wave run-up level is defined as the total sum of the mean sea level, the runup level of infragravity waves and that of incident wind waves. Katoh and Yanagishima (1993) proposed an equation for estimating the wave run-up level $R_{E}$, which had been empirically derived from field observation data obtained at HORS.

$$
R_{E}=\bar{\eta}_{0}+0.96 H_{L}+0.31[\text { D.L., } \mathrm{m}]
$$

where $\bar{\eta}_{0}$ is the mean sea level and $H_{L}$ is the height of the infragravity waves at the shoreline. The second and third terms on the right hand side of the equation are considered to present the run-up heights caused by the effect of infragravity waves and incident wind waves, respectively.

\section{SHORT-TERM SWASH ZONE BEACH PROFILE CHANGE MODEL}

The model for estimating the cross-shore distribution of the cross-shore sediment transport rate on the foreshore consists of two steps. The first step is to determine whether a berm is formed or eroded (developed or decayed) on the basis of the wave run-up elevation. The second step is to estimate the cross-shore sediment transport rate using two different sub-models; one is for berm formation (development) and the other is for erosion (decay).

\section{Threshold for Berm Formation and Erosion}

Katoh and Yanagishima (1992) suggested that the berm erosion occurs when enhanced wave runup passes through the berm crest. Thus, here, the threshold between the berm formation and the berm erosion was decided by the correlation between the berm crest elevation and the maximum wave runup elevation.

$$
R_{E}=0.634 B_{E}+0.814
$$

where $R_{E}$ is the wave run-up elevation and $B_{E}$ is the berm crest elevation.

Once the wave run-up level elevation, which is calculated from Eq. 3, exceeds the berm crest elevation, the berm erosion occurs. In contrast, when the wave run-up level is below the berm crest elevation, the berm formation occurs. The details can be found in Suzuki and Kuriyama (2008).

\section{Modeling of Cross-shore Sediment Transport Rate}

Based on the daily beach profile data, the topography changes of berm formation and berm erosion were selected. Katoh and Yanagishima (1992) identified 219 cases of berm formation and 58 cases of berm erosion from the 2.5-year (from August 1987 to January 1990) beach profile data set obtained at HORS. By using these data, Suzuki and Kuriyama (2008) proposed spatial distributions of cross-shore sediment transport rates for berm formation and erosion.

In this study, the investigation area is set to include the areas of berm formation and erosion. The onshore boundary is defined at the maximum wave run-up position, and the offshore boundary is defined at the shoreline position of the mean tide level (D.L., $0.65 \mathrm{~m}$ ). The offshore and onshore boundary positions varied owing to wave conditions and beach profile changes. Therefore, the crossshore positions are normalized by using the distance between the boundaries, $X$. Namely, the onshore boundary is set as $x / X=0.0$ and the offshore boundary is set as $x / X=1.0$.

For the berm formation case, the landward sediment transport rate gradually increases from $x / X=$ 0.0 to $x / X=0.7$ and takes a steady value at the seaward of $x / X=0.7$. The spatial distribution of sediment transport rate for berm formation from $x / X=0.0$ to $x / X=0.7$, where the sediment transport rate takes a steady value, was formed as a quadratic curve. The curve starts from the origin $(x / X=0.0$, $Q=0.0$ ) and increases until the rate at $x / X=0.7$, which is decided by Eq. (4). The rates from $x / X=0.7$ to 1.0 are assumed to be constant with the rate at $x / X=0.7$.

$$
Q_{f_{-} 0.7}=1.15 \times 10^{-7} E_{f}+0.49
$$

where $Q_{f 0.7}$ is the sediment transport rate at $x / X=0.7$ for berm formation.

On the other hand, during the berm erosion, initially, the run-up wave washes sediment over the berm crest and sediments are transported landward. For this reason, the landward sediment transport rate has a high peak at $x / X=0.15$ and sediment accumulation occurs from $x / X=0.0$ to 0.15 . Next, the run-up water moves seaward with eroding the berm. Therefore, seaward of the peak of the landward sediment transport rate, the sediment transport rate changes the direction to the seaward at $x / X=0.26$ and decreases until around $x / X=0.7$. From $x / X=0.7$, the rate becomes steady. The spatial distribution of the sediment transport rate for berm erosion from $x / X=0.0$ to $x / X=1.0$ was formed as follows. The model is formed as a cubic curve which starts from the origin $(x / X=0.0, Q=0.0)$, goes through the 
rate at $x / X=0.15$ and ends at the rate at $x / X=0.7$. The rates at $x / X=0.15$ and $x / X=0.7$ are decided by Eqs. (5) and (6), respectively. The rates from $x / X=0.7$ to 1.0 are assumed to be constant with the rate at $x / X=0.7$.

$$
\begin{aligned}
& Q_{e_{-} 0.15}=2.06 B_{h}-0.29 \\
& Q_{e_{-} 0.7}=-3.07 B_{h}-1.17
\end{aligned}
$$

where $Q_{e_{0} .15}$ and $Q_{e_{0.7}}$ are the sediment transport rates at $x / X=0.15$ and 0.7 for berm erosion, respectively, and $B_{h}$ is the berm height. The details can be found in Suzuki and Kuriyama (2008).

\section{Estimation of the Shoreline Position Fluctuation}

The cross-shore distribution of the cross-shore sediment transport rate for berm formation was modeled with the offshore wave energy flux (Eq. 4), and for berm erosion was modeled with the berm height (Eqs. 5 and 6). In this short-term swash zone beach profile change model, the offshore boundary was defined at the shoreline position of the mean tide level. Therefore, at first, the movement of the shoreline position was modeled.

It was reported that shoreline position can be estimated by using the wave energy flux (e.g., Katoh and Yanagishima, 1988; Kench and Brander, 2006). Figure 3 shows the relationships between the offshore wave energy flux and the shoreline position of the mean tide level. From the figure, a good

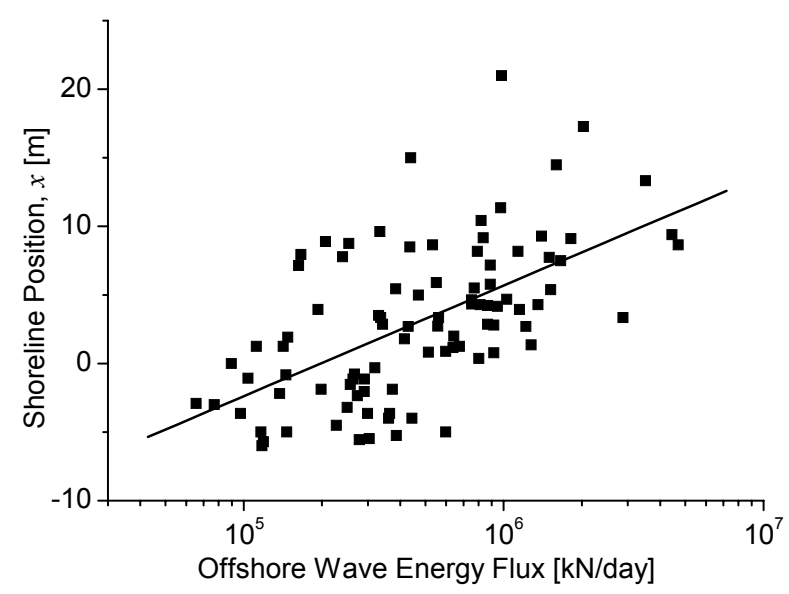

Figure 3. Relationship between the offshore energy flux and the shoreline position at the mean tide level.

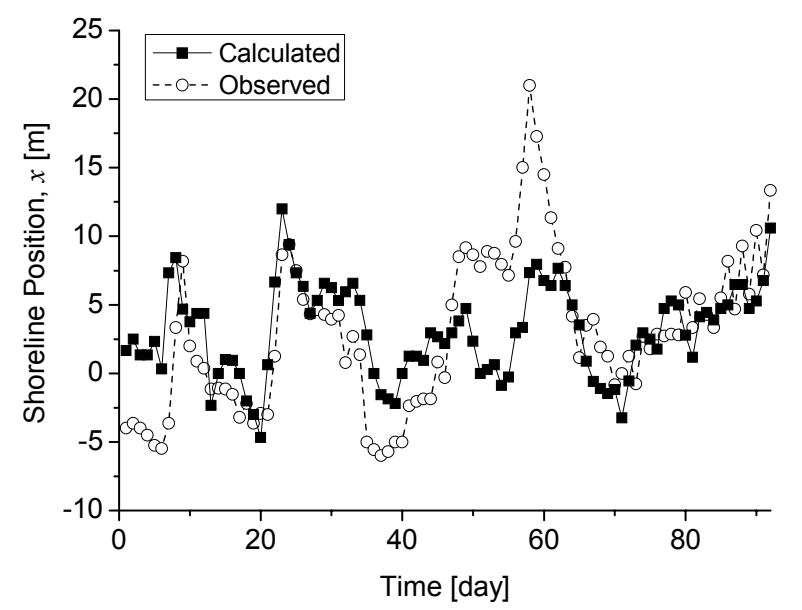

Figure 4. Temporal distributions of shoreline positions at the mean tide level of calculated results and observed data. 
correlation can be seen between the two $(R=0.58)$. The shoreline position moved seaward when the offshore wave energy flux increased. This correlation can be considered as follows. During severe wave conditions, the wave run-up elevation increases and the sediments on land were transported seaward direction. Due to this reason, the sediment accumulation occurs around the shoreline position of the mean tide level.

Therefore, in this study, the offshore boundary position (i.e., the shoreline position of the mean tide level) was estimated by the offshore wave energy flux. Figure 4 shows the temporal distributions of calculated results and observed data of shoreline positions at the mean tide level. Although the gaps between the two were relatively large at the first seven days and from a 45-day to a 60-day, the model well predict the fluctuation of the shoreline position throughout the three months.

\section{CALCULATION OF SHORT-TERM SWASH ZONE BEACH PROFILE CHANGE}

The model was applied for the calculation of a three-month (from May 1, 1988 to July 31, 1988) foreshore beach profile change, and compared with the observed data. The beach profile on May 1, 1988 was set as the initial beach profile.

The temporal distributions of the day-averaged offshore wave height, wave period and calculated offshore wave energy flux from May 1, 1988 to July 31, 1988 were shown in Fig. 5. Relatively large waves were observed on May 23rd. During these three months, the averaged offshore significant wave

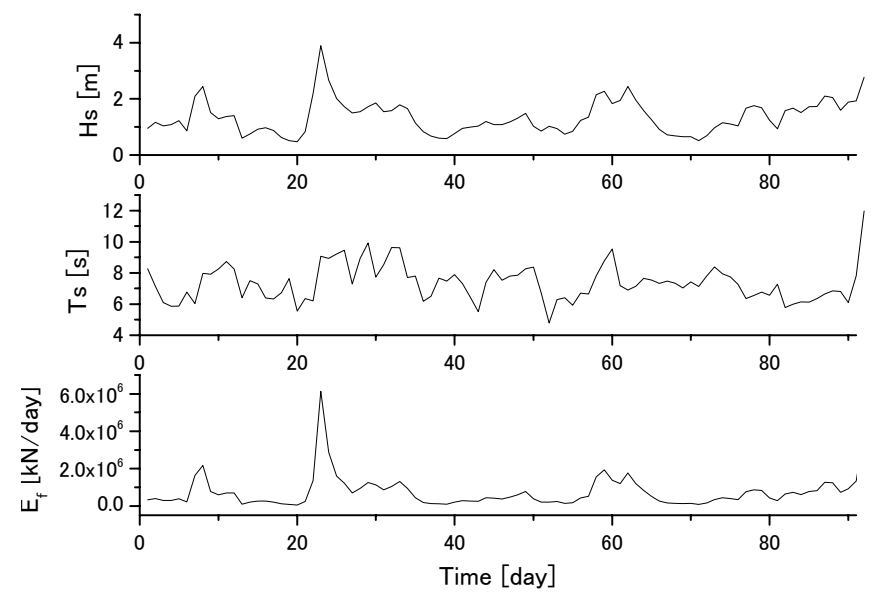

Figure 5. Temporal distributions of the wave height, Hs, wave period, Ts, and wave energy flux, $E_{f}$ from May 1 , 1988 to July $31,1988$.

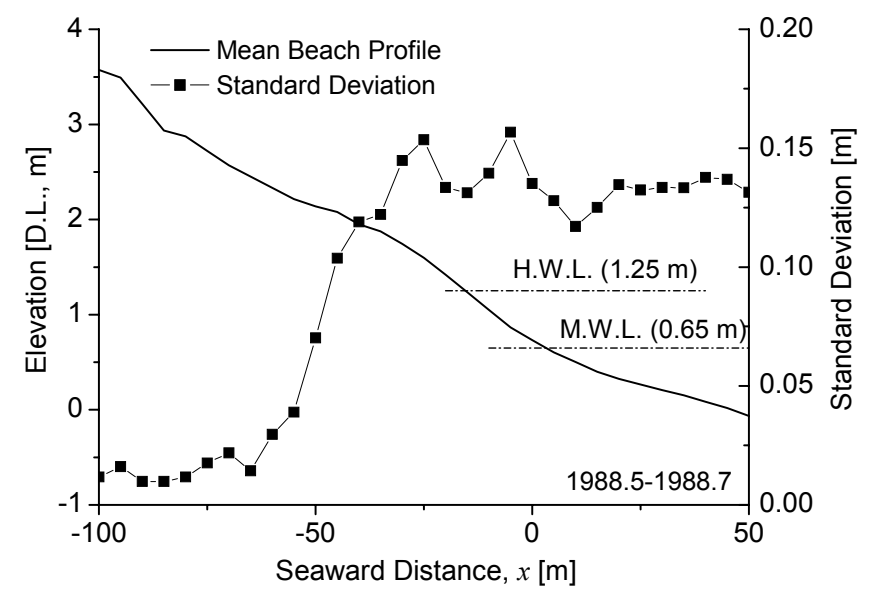

Figure 6. Mean beach profiles and its standard deviations. 


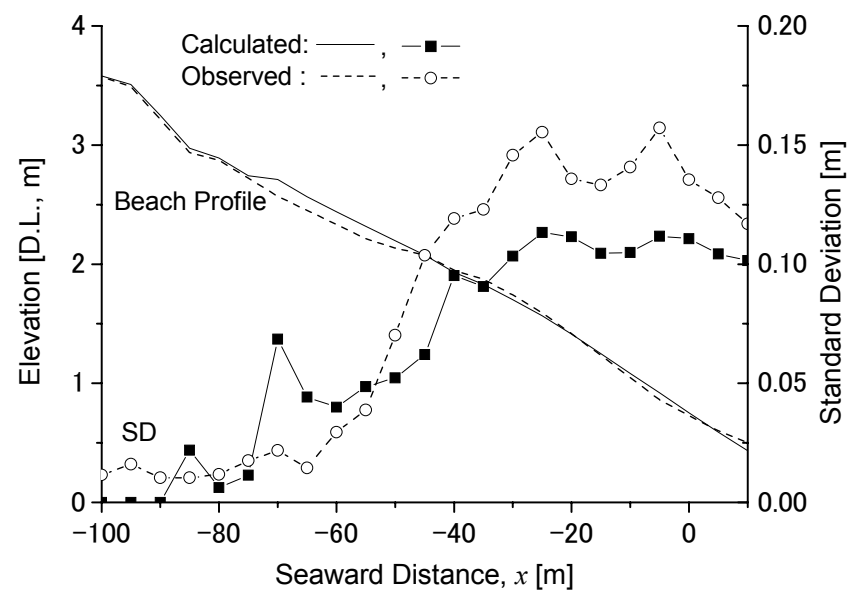

Figure 7. Mean beach profiles and its standard deviations of calculated results and observed data.
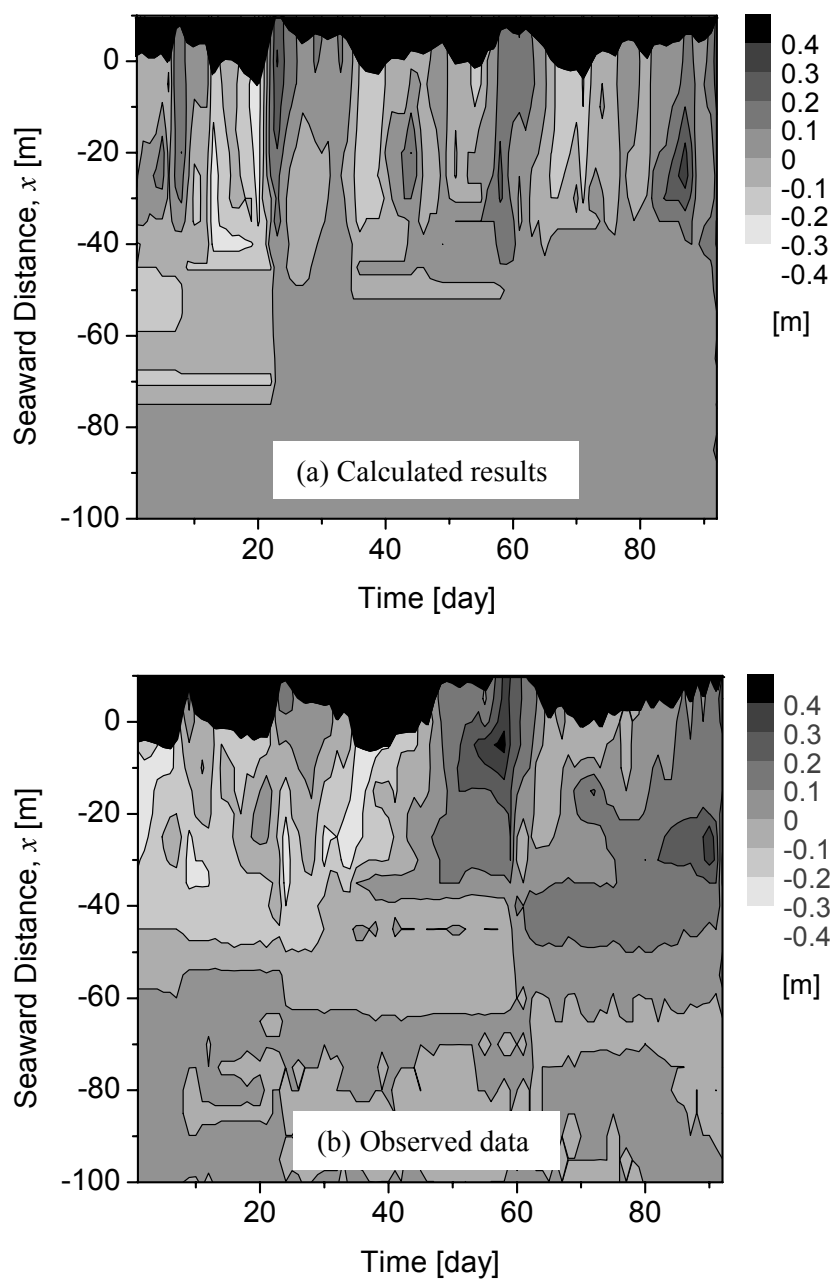

Figure 8. Deviations from the mean beach profiles (a) calculated results, (b) Observed data. 
height and period were $1.34 \mathrm{~m}$ and $7.36 \mathrm{~s}$, respectively. Figure 6 shows the mean beach profile and its standard deviation, which were calculated from the observed data. The values of standard deviation were rapidly increased from $x=-60 \mathrm{~m}$ and the values became about $0.14 \mathrm{~m}$ at the seaward of $x=-30 \mathrm{~m}$. The averaged shoreline positions and the averaged beach slopes at the mean and high tide levels were $3.2 \mathrm{~m}, 0.025$ and $-15.4 \mathrm{~m}, 0.037$, respectively.

The mean beach profiles and the standard deviations of the observed data and the calculated results were shown in Fig. 7. For the beach profiles, the calculated results from $x=70 \mathrm{~m}$ to $-45 \mathrm{~m}$ show higher values compared to the observed data. In the calculation, the onshore boundary position is decided by the estimated maximum wave run-up elevation (i.e., Eq. 2). However, in reality, the maximum wave run-up elevation changes wave by wave. This is a reason of the differences between the two. For the standard deviations, the calculated results under estimate at the offshore than $x=-45 \mathrm{~m}$. However, the trend of the curve is in good agreement.

The calculated results and observed data of the deviations from the mean beach profiles are shown in Fig. 8 (a) and (b), respectively. Since the offshore boundary was defined at the shoreline position of the mean tide level, the area seaward of the boundary is colored in black. Although there are some differences between the two, the calculated results show nearly the same beach profile change of berm formations, where from a 45-day to a 60-day and a 70-day to a 90-day and erosions, where a 10-day to a 20-day, a 35-day to a 40-day and a 60-day to a 70-day, in a qualitative sense.

Figure 9 shows the temporal distributions of shoreline positions of the high tide level (D.L., 1.25 $\mathrm{m})$. Although the calculated results sometimes show both over and under estimations, the trend of the calculated results is basically the same as the observed data. The temporal distributions of beach slopes around the high tide level are shown in Fig. 10. Although the calculated beach slopes show milder than the observed beach slopes, the variation trend is in good agreement. The beach slope increases when the shoreline position moves seaward direction in most settings.

\section{CONCLUSIONS}

The short-term swash zone beach profile change model focusing on berm formation and erosion was developed by using the 2.5 -year beach profile data obtained at HORS. The investigation area is normalized by the distance from the onshore boundary, where the intersection point of the maximum wave run-up elevation and the beach profile, to the offshore boundary, where the shoreline position of the mean tide level. The conclusions obtained in the present study are as follows: (1) A short-term swash zone beach profile change model focusing on berm formation and erosion was proposed. The sediment transport rate for berm formation and erosion are modeled by using the wave energy flux and the berm height, respectively. (2) During the three months calculation, the model can well predict the trend of the beach profile changes of berm formation and erosion in a qualitative sense. (3) Although the calculated beach slopes show milder than the observed beach slopes, the variation trend is in good agreement.

\section{ACKNOWLEDGMENTS}

The authors thank all the staff members at HORS for conducting the field surveys. They also thank the Marine Information Division, Port and Airport Research Institute and Kashima Port and Airport Construction Office for allowing use of the wave data of the Port of Kashima.

\section{REFERENCES}

Baldock, T.E., P. Kim Son, P. Manoonvoravong, M.P. Barnes, and J.M. Alsina. 2007. Probabilisticdeterministic modeling of swash zone morphology, Coastal Sediments' 07, ASCE, 272-285.

Katoh, K., and S. Yanagishima. 1988. Predictive model for daily changes of shoreline, Proc. 21 st Int. Conf. Coastal Eng., ASCE, 1253-1264.

Katoh, K., and S. Yanagishima. 1992. Berm formation and berm erosion, Proc. 23rd Int. Conf. Coastal Eng., ASCE, 2136-2149.

Katoh, K., and S. Yanagishima. 1993. Beach erosion in a storm due to infragravity waves, Rep. of PHRI, 31, 5, 73-102.

Kench, P.S., and R.W. Brander. 2006. Response of reef island shorelines to seasonal climate oscillations: South Maalhosmadulu atoll, Maldives, J. Geophys. Res. F: Earth Surface, 111, 1, F01001, doi: 10.1029/2005 JF000323.

Larson, M., S. Kubota, and L. Erikson. 2004. Swash-zone sediment transport and foreshore evolution: field experiments and mathematical modeling, Marine Geology, 212, 61-79. 
Osborne, P.D., and G.A. Rooker. 1997. Surf zone and swash zone sediment dynamics on high energy beaches: West Auckland New Zealand, Coastal Dynamics '97, 814-823.

Puleo, J.A., R.A. Beach, R.A. Holman, and J.S. Allen. 2000. Swash zone sediment suspension and transport and the importance of bore-generated turbulence, J. Geophys. Res., 105, C7, 1702117044.

Suzuki, T., M. Takeuchi, N. Tomoda, S. Yamaguchi, and Y. Kuriyama. 2007. Spatial distribution of cross-shore sediment transport rate for berm formation and erosion, Coastal Sediments '07, ASCE, 2037-2048.

Suzuki, T., and Y. Kuriyama. 2008. Simple model of cross-shore sediment transport rate for berm formation and erosion, Proc. 31st Int. Conf. Coastal Eng., ASCE, 1762-1773.

Thomas, K.V., and M. Baba. 1986. Berm development on a monsoon-influenced microtidal beach, Sedimentology, 33, 4, 537-546. 